\title{
Fitase na dieta de alevinos de carpa húngara: desempenho e características de carcaça
}

[Phytase in diet of common carp fingerlings: produtive performance and carcass traits]

\author{
C.B. Rocha ${ }^{1}$, J.L.F. Pouey ${ }^{2}$, S.R.N. Piedras ${ }^{2}$, D.B.S. Enke ${ }^{3}$, J.M. Fernandes ${ }^{1}$ \\ ${ }^{1}$ Aluno de pós-graduação em Zootecnia - UFPel - Pelotas, RS \\ ${ }^{2}$ Departamento de Zootecnia - UFPel - Pelotas, RS \\ ${ }^{3}$ Pós-doutorado em Aquicultura - UFSC - Florianópolis, SC
}

\begin{abstract}
RESUMO

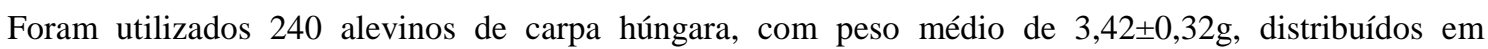
delineamento inteiramente ao acaso, com quatro tratamentos e quatro repetições. A dieta basal foi formulada com ingredientes de origem vegetal (36\% de proteína bruta e 3.200kcal de energia digestível). Os tratamentos corresponderam a quatro níveis de fitase ativa (UF) por kg na dieta: zero (controle), 500, 1000 e $1500 \mathrm{UF} / \mathrm{kg}$. A cada 15 dias, foi realizada uma biometria e, ao término do período experimental (45 dias), 5\% dos animais foram eutanasiados para determinação do rendimento de carcaça e composição químico-bromatológica. Os parâmetros de desempenho avaliados foram: peso final, ganho de peso, comprimento total, taxa de crescimento específico e sobrevivência. A suplementação de fitase não influiu no desempenho produtivo, entretanto melhorou significativamente as características da carcaça.
\end{abstract}

Palavras-chave: peixe, Cyprinus carpio, fitato, antinutricional, fósforo

\begin{abstract}
A total of 240 fingerlings, with initial average weight $3.42 \pm 0.32 \mathrm{~g}$, were distributed in a completely randomized experimental design, with four treatments and four replicates. Basal diet consisted of vegetal ingredients (36\% crude protein and 3,220kcal of digestible energy). Treatments corresponded to four levels of active phytase (UF) per $\mathrm{kg}$ of diet: zero (control), 500, 1,000, and 1,500. Every 15 days, a biometry was made and at the end of the experimental period (45 days) $5 \%$ of animals were euthanized to determine carcass yield and chemical-bromatologic composition. The following variables were evaluated: final weight, weight gain, total length, specific growth rate, and survial. There was no effect of phytase on productive performance; however, it significantly improved carcass characteristics.
\end{abstract}

Keywords: fish, Cyprinus carpio, phytate, antinutritional, phosphorus

\section{INTRODUÇÃO}

A aquicultura apresenta-se como uma excelente opção para a crescente demanda de proteínas de origem animal. Atualmente, a produção de alimentos dessa atividade vem gerando profunda atenção da sociedade, levando ao desenvolvimento de pesquisas sobre a qualidade sanitária do alimento, o sistema de produção utilizado e o impacto causado no ambiente (Suárez-Mahecha et al., 2002).
Nos alimentos de origem vegetal, o fósforo está presente em grande quantidade na forma fitato, que é de baixa disponibilidade e quelante de alguns cátions bivalentes como $\mathrm{Ca}, \mathrm{Fe}, \mathrm{Mg}, \mathrm{Zn}$ (Surek et al., 2008). Uma vez que o fósforo (P) é um elemento essencial em rações para peixes (Nutrient ..., 1993), sua concentração na dieta deve atender às exigências necessárias para 0 bom desempenho. A suplementação de $\mathrm{P}$ inorgânico na dieta é necessária, mas eleva o custo da ração e, quando em excesso, aumenta o risco de poluição ambiental. O P não digerido é

Recebido em 16 de setembro de 2009

Aceito em 11 de outubro de 2010

E-mail: cbr.vet@gmail.com 
liberado via excreta e pode estimular a eutrofização, que é o excessivo crescimento de algas e fitoplâncton em meios aquáticos (OlivaTeles et al., 1998). Sendo assim, a redução na quantidade de nutrientes liberados no meio ambiente tem grande importância para a aquicultura intensiva (Cheng e Hardy, 2002).

A adição de fitase na dieta tem sido usada com sucesso, obtendo-se melhora na digestibilidade dos nutrientes (Cao et al., 2007). De acordo com Moreira et al. (2009), a enzima fitase atua catabolizando as moléculas de fitato, disponibilizando o fósforo e outros minerais para absorção, metabolismo e retenção nos ossos. No Brasil, muitas pisciculturas utilizam a carpa húngara (Cyprinus carpio) devido à sua rusticidade, resistência a diferentes temperaturas e facilidade de criação (Queirol et al., 2005). O objetivo deste estudo foi avaliar o efeito da suplementação de diferentes níveis de fitase sobre o desempenho produtivo e as características de carcaça em alevinos de carpa húngara.

\section{MATERIAL E MÉTODOS}

Foram utilizados 240 alevinos de carpa húngara, com peso inicial médio de 3,42 $\pm 0,32 \mathrm{~g}$, distribuídos em um delineamento inteiramente ao acaso, com quatro tratamentos e quatro repetições. Cada unidade experimental era composta por um aquário com 30 litros de água, 15 alevinos e sistema de oxigenação por pedra porosa acoplada a um soprador de ar. As dietas experimentais foram formuladas somente com ingredientes de origem vegetal e continham, em média, 35\% de proteína bruta e $3.200 \mathrm{kcal} / \mathrm{kg}$ de energia digestível. A fitase foi incluída em níveis de zero (controle), 500, 1000 e 1500 unidades de fitase por $\mathrm{kg}$ de dieta $(\mathrm{UF} / \mathrm{kg})$.

Procedeu-se à mistura dos ingredientes, seguida da adição da fitase diluída em água morna $\left(42^{\circ} \mathrm{C}\right)$ e, logo após, foram realizadas nova mistura, peletização e secagem em estufa a $50^{\circ} \mathrm{C}$. Ao término da secagem, uma amostra da dieta foi retirada para determinação da composição bromatológica (Tab. 1).

Os parâmetros limnológicos da água foram verificados diariamente, mantendo-se dentro dos padrões recomendados para a espécie: temperatura média $\left(22,52^{\circ} \mathrm{C}\right)$, oxigênio dissolvido $(6,50 \mathrm{mg} / \mathrm{L})$, $\mathrm{pH}(7,86)$. A cada dois dias, realizava-se a troca de $30 \%$ da água, sifonando-se os restos da dieta e excretas.

Tabela 1. Composição das dietas experimentais usadas para alevinos de carpa húngara

\begin{tabular}{|c|c|}
\hline Ingrediente & $(\%)$ \\
\hline Farelo de soja & 36,00 \\
\hline Levedura de cana & 36,00 \\
\hline Milho triturado & 9,00 \\
\hline Óleo de soja & 7,00 \\
\hline Farelo de trigo & 6,00 \\
\hline Premix vitamínico e mineral $^{1}$ & 5,00 \\
\hline Sal comum iodado & 1,00 \\
\hline Fitase & Variável \\
\hline Total & 100,00 \\
\hline \multicolumn{2}{|l|}{ Composição química (\%) } \\
\hline Matéria seca & 87,99 \\
\hline Proteína bruta & 36,80 \\
\hline Extrato etéreo & 10,26 \\
\hline Cinzas & 6,40 \\
\hline Energia digestível (kcal/kg)* & 3200 \\
\hline \multicolumn{2}{|c|}{ 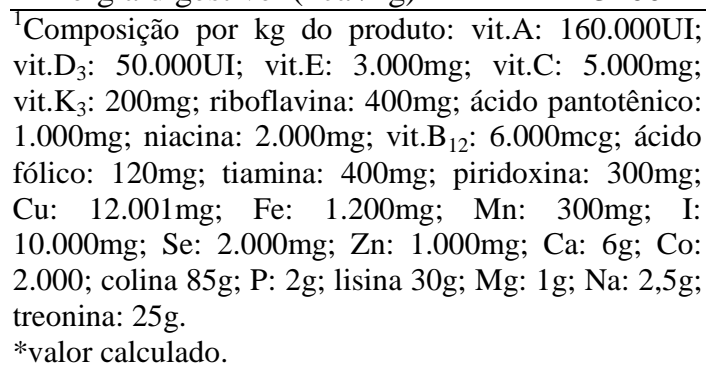 } \\
\hline
\end{tabular}

A alimentação foi ministrada duas vezes ao dia, na proporção de $10 \%$ da biomassa total, e, a cada 15 dias, foram realizadas avaliações de peso e medida do comprimento dos peixes. Os parâmetros de desempenho avaliados foram: peso final, ganho de peso (GP), comprimento total (CT), taxa de crescimento específico (TCE), rendimento de carcaça (RC) e sobrevivência (S). Ao término do período experimental de 45 dias, procedeu-se à eutanásia de uma amostragem de 5\% dos animais para avaliação do rendimento de carcaça e composição corporal, conforme AOAC (Official ..., 1995).

Os resultados foram submetidos à análise de variância e regressão polinomial por meio do programa Statistica ${ }^{\circledR}$ 5.0.

\section{RESULTADOS E DISCUSSÃO}

A média de peso final geral aos 45 dias de experimento foi de 5,11g, sem diferença 
( $\mathrm{P}>0,05)$ entre os tratamentos estudados (Tab. 2). De acordo com Gonçalves et al. (2007), o nível ideal de fitase para a maioria dos peixes está acima de 2000UF/kg para melhorar a disponibilidade de fósforo orgânico. Furuya et al.
(2001) concluíram que a utilização de ração com $700 U F / k g$ é adequada para o desempenho produtivo, aumentando a digestibilidade da proteína, do cálcio e do fósforo na fase inicial de vida da tilápia-do-nilo (Oreochromis niloticus).

Tabela 2. Desempenho produtivo de alevinos de carpa húngara (Cyprinus carpio) alimentados com diferentes níveis de fitase na dieta

\begin{tabular}{lccccc} 
& \multicolumn{4}{c}{ Fitase (UF/kg de dieta) } & \multirow{2}{*}{ P } \\
\cline { 2 - 4 } Variável & 0 & 500 & 1000 & 1500 & - \\
Peso inicial (g) & $3,45 \pm 0,32$ & $3,41 \pm 0,32$ & $3,38 \pm 0,30$ & $3,44 \pm 0,31$ & \\
Peso final (g) & $5,11 \pm 0,76$ & $5,05 \pm 0,65$ & $5,03 \pm 0,73$ & $5,28 \pm 0,65$ & 0,19 \\
GP (g) & $1,65 \pm 0,16$ & $1,63 \pm 0,23$ & $1,64 \pm 0,36$ & $1,84 \pm 0,21$ & 0,63 \\
CT (cm) & $6,90 \pm 0,22$ & $7,12 \pm 0,45$ & $7,05 \pm 0,27$ & $7,17 \pm 0,20$ & 0,14 \\
TCE (\%) & $0,86 \pm 0,04$ & $0,87 \pm 0,11$ & $0,88 \pm 0,16$ & $0,95 \pm 0,09$ & 0,73 \\
RC (\%) & $88,18 \pm 1,73$ & $89,37 \pm 1,43$ & $88,85 \pm 1,38$ & $89,18 \pm 1,41$ & 0,07 \\
SOB (\%) & 100 & 100 & 100 & 100 & - \\
\hline
\end{tabular}

GP: ganho de peso; CT: comprimento total; TCE: taxa de crescimento específico; RC: rendimento de carcaça, SOB: sobrevivência.

O GP, CT, RC e TCE também não foram diferentes $(\mathrm{P}>0,05)$ entre os tratamentos. Resultados semelhantes foram observados por Bock et al. (2007), em que níveis de 1000 a 2000UF/kg na dieta da tilápia-do-nilo não melhoraram o desempenho produtivo, apesar de reduzirem os níveis de fósforo nas fezes. Nwanna e Schwarz (2007) testaram a inclusão de três níveis de fitase (1000, 2000 e 4000UF/kg) na dieta da carpa comum e não observaram efeito sobre o desempenho. Esses autores sugeriram níveis maiores de fitase para uma possível melhora no desempenho produtivo. Sardar et al. (2007) concluíram que a suplementação de apenas $500 \mathrm{UF} / \mathrm{kg}$ na dieta da carpa comum pode substituir a suplementação de fosfato bicálcico, premix micromineral, lisina e metionina, sem comprometer integralmente o desempenho produtivo dos peixes. Furuya et al. (2005) concluíram, do mesmo modo, que 500UF/kg melhoram o desempenho produtivo e a retenção de minerais nos ossos de tilápias nilóticas na fase de terminação.

A temperatura e o $\mathrm{pH}$ ideal para atividade da fitase é de $55^{\circ} \mathrm{C}$ e 5,3 , respectivamente, sendo que a taxa de atividade de hidrólise da enzima é muito mais rápida a $37^{\circ} \mathrm{C}$ do que a $15^{\circ} \mathrm{C}$ (Sugiura et al., 2001). Baruah et al. (2007) relataram que, em peixes carnívoros, o baixo $\mathrm{pH}$ estomacal facilita a ação de enzimas digestivas, inclusive a fitase. Em peixes onívoros, como a carpa, esse mecanismo é reduzido, devido à ausência de estômago ativo. Como alternativa, poderiam ser utilizados ácidos orgânicos ou acidificantes na dieta para melhorar a atividade enzimática (Li et al., 2008). Segundo Baruah et al. (2005), a adição de 3\% de ácido cítrico e de 500UF/kg na dieta melhora a disponibilidade e a retenção óssea de minerais para juvenis de carpa indiana (Labeo rohita). Para Cao et al. (2008), o pré-tratamento da ração com $1000 \mathrm{UF} / \mathrm{kg}$ pode aumentar a disponibilidade do fósforo de $1,5 \mathrm{~g} / \mathrm{kg}$ para $4,01 \mathrm{~g} / \mathrm{kg}$ em dietas à base de vegetais. O pré-tratamento das dietas com fitase, ou a inclusão de ácidos orgânicos, pode ser uma alternativa para melhorar o efeito desta enzima em ciprinídeos. É importante mencionar, também, que a ação e o resultado dos níveis de fitase empregados estão relacionados com o valor biológico dos alimentos, a natureza e a quantidade de ácido fítico que estes possam conter (Gonçalves et al., 2004).

A suplementação de fitase na dieta no presente experimento não interferiu na taxa de sobrevivência, o que também foi observado por Furuya et al. (2001) para tilápia-do-nilo.

A proteína bruta e a umidade na carcaça não diferiram $(\mathrm{P}>0,05)$ entre os tratamentos (Tab. 3). Bock et al. (2007) também não observaram efeito da fitase sobre a retenção proteica para tilápiado-nilo. O efeito dos níveis de fitase sobre as características de carcaça de peixes provavelmente tenha maior relevância sobre a deposição mineral, em decorrência da maior disponibilidade de fósforo livre suplementar. 
Fitase na dieta de alevinos...

Tabela 3. Composição química da carcaça de alevinos de carpa húngara alimentados com diferentes níveis de fitase na dieta

\begin{tabular}{lcccc}
\hline Fitase (UF/kg) & $\begin{array}{c}\text { Proteína } \\
\text { bruta }\end{array}$ & $\begin{array}{c}\text { Extrato } \\
\text { etéreo }\end{array}$ & Cinzas & Umidade \\
\hline 0 & $62,22 \pm 1,38$ & $25,68 \pm 0,14$ & $14,68 \pm 0,06$ & $78,69 \pm 0,21$ \\
500 & $63,23 \pm 1,33$ & $23,20 \pm 0,02$ & $14,95 \pm 0,04$ & $80,05 \pm 0,87$ \\
1000 & $61,75 \pm 1,34$ & $22,00 \pm 0,04$ & $15,35 \pm 0,34$ & $79,32 \pm 0,51$ \\
1500 & $62,56 \pm 1,09$ & $24,37 \pm 0,38$ & $15,03 \pm 0,30$ & $79,09 \pm 0,62$ \\
$P$ & 0,58 & $0,0001^{*}$ & $0,048^{*}$ & 0,07 \\
\hline
\end{tabular}

P: probabilidade; * $(\mathrm{P}<0,05)$; médias seguidas do desvio-padrão, $(\mathrm{n}=3)$.

Foi observado efeito quadrático $(\mathrm{P}<0,05)$ dos níveis de fitase sobre porcentagem de cinzas na carcaça, sendo que 1000UF/kg resultaram em aumento de 0,67\% na deposição mineral em relação à dieta-controle (Fig. 1).

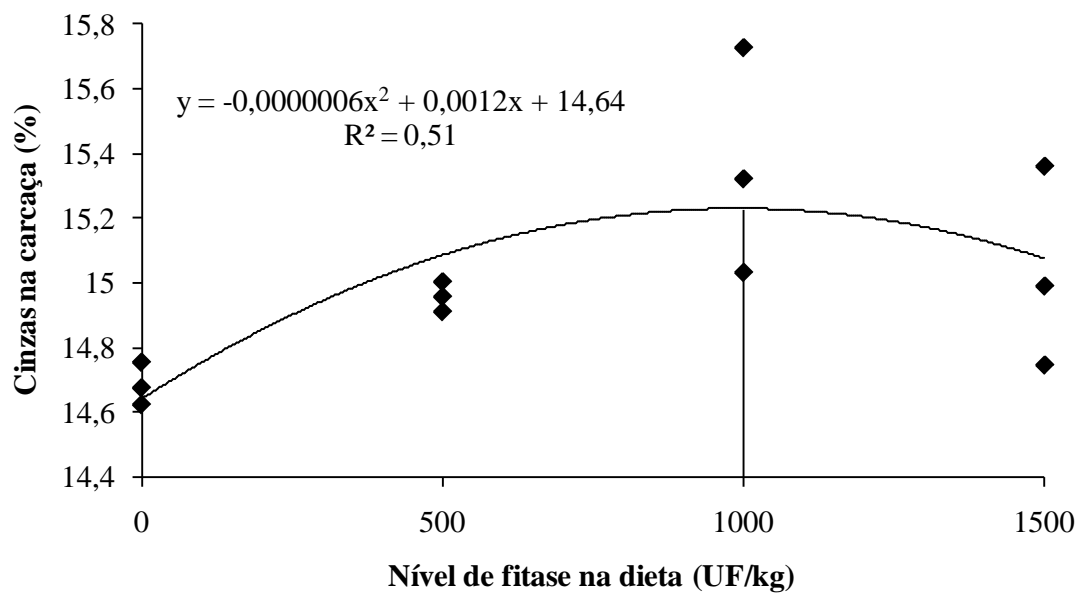

Figura 1. Cinzas na carcaça de alevinos de carpa húngara submetidas a níveis crescentes de fitase na dieta.

Este resultado assemelha-se ao obtido por Furuya et al. (2008), em que o acréscimo de fitase (0 a 2000UF/kg) aumentou linearmente as cinzas na carcaça de juvenis de pacu (Piaractus mesopotamicus). Esses autores também observaram aumento nos níveis de cálcio e fósforo ósseo. Biswas et al. (2007) não observaram diferença na umidade, cinzas e lipídio na carcaça de juvenis de red sea bream (Pagrus major) submetidos a dietas com 1000 a
4000UF $/ \mathrm{kg}$. Os resultados deste experimento também diferem dos obtidos por Nwanna e Schwarz (2008), que suplementaram níveis de 500 a $1000 \mathrm{UF} / \mathrm{kg}$ para carpa comum e não observaram diferença nas cinzas da carcaça.

O extrato etéreo na carcaça reduziu à medida que foram aumentados os níveis de fitase na dieta, pelo ajuste polinomial observa-se que $830 \mathrm{UF} / \mathrm{kg}$ resultaram em efeito mais acentuado (Fig. 2). 


\section{Rocha et al.}

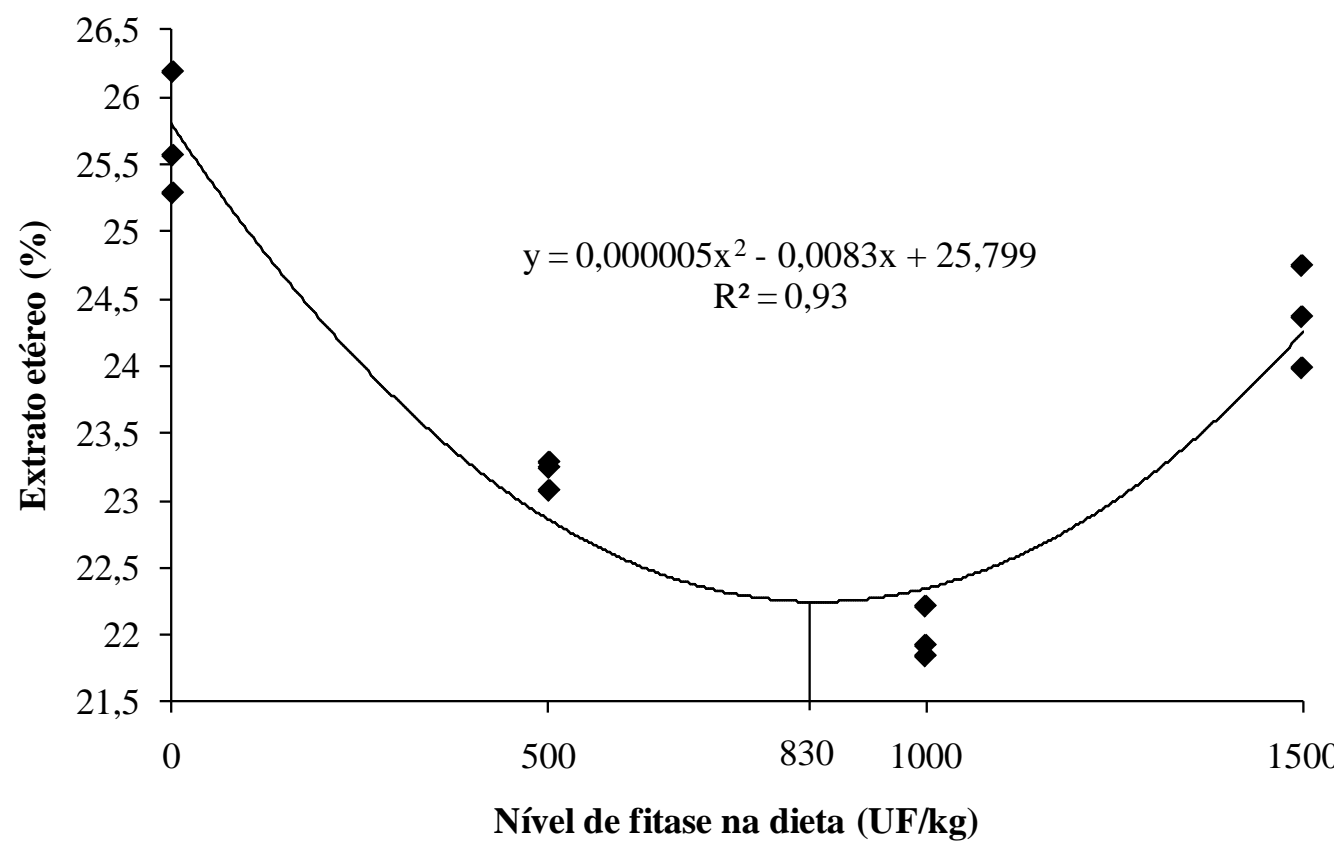

Figura 2. Níveis de extrato etéreo na carcaça de alevinos de carpa húngara submetidas a níveis crescentes de fitase na dieta.

Semelhante aos resultados do presente experimento, Pezzato et al. (2006) e Furuya et al. (2008) verificaram aumento nas cinzas e redução no teor de extrato etéreo na carcaça da tilápia-donilo em função de níveis crescentes de fósforo disponível na dieta. Zhang et al. (2006) também relataram redução linear da porção lipídica da carcaça de juvenis de seabass japonês (Lateolabrax japonicus), alimentados com níveis crescentes de fósforo na dieta. Silva et al. (2007) observaram efeito quadrático dos níveis de fitase sobre o extrato etéreo na carcaça da tilápia-donilo, e o efeito máximo foi atingido com 647UF/kg. Para alevinos de jundiá (Rhamdia quelen), níveis de 500 a $1500 \mathrm{UF} / \mathrm{kg}$ reduziram linearmente a deposição de gordura corporal da carcaça (Rocha et al., 2007). Provavelmente a maior disponibilidade de fósforo favoreceu o metabolismo energético dos ácidos graxos ( oxidação), pois esse mineral participa como constituinte da molécula de adenosina trifosfato (ATP). Observa-se, no presente experimento, que a suplementação de fitase, dentro dos níveis empregados, mesmo que não tenha afetado o desempenho produtivo, melhorou as características de carcaça.

\section{CONCLUSÕES}

A suplementação de até $1500 \mathrm{UF} / \mathrm{kg}$ não afeta o desempenho produtivo, entretanto 1000UF/kg aumentam as cinzas e $830 \mathrm{UF} / \mathrm{kg}$ reduzem o extrato etéreo da carcaça em alevinos de carpa húngara.

\section{REFERÊNCIAS BIBLIOGRÁFICAS}

BARUAH, K.; PAL, A.K.; SAHU, N.P. et al. Dietary protein level, microbial phytase, citric acid and their interactions on bone mineralization of Labeo rohita (Hamilton) juveniles. Aquacult. Res., v.36, p.803-812, 2005.

BARUAH, K.; SAHU, N.P.; PAL, A.K. et al. Dietary microbial phytase and citric acid synergistically enhances nutrient digestibility and growth performance of Labeo rohita (Hamilton) juveniles at sub-optimal protein level. Aquacult. Res., v.38, p.109-120, 2007.

BISWAS, A.K.; KAKU, H.; JI, S.C. et al. Use of soybean meal and phytase for partial replacement of fish meal in the diet of red sea bream, Pagrus major. Aquaculture, v.267, p.284-291, 2007. 
BOCK, C.L.; PEZZATO, L.E.; CANTELMO, O.A. et al. Fitase em rações para tilápia-do-nilo na fase de crescimento. Rev. Bras. Zootec., v.36, p.1455-1461, 2007.

CAO, L.; WANG, W.M.; YANG, C.T. et al. Application of microbial phytase in fish feed. Enz. Mic. Tech., v.40, p.497-507, 2007.

CAO, L.; YANG, Y.; WANG, W.M. et al. Effects of pretreatment with microbial phytase on phosphorous utilization and growth performance of Nile tilapia (Oreochromis niloticus). Aquacult. Nutrit., v.14, p.99-109, 2008.

CHENG, Z.J.; HARDY, R.W. Effect of microbial phytase on apparent nutrient digestibility of barley, canola meal, wheat and wheat middlings, measured in vivo using rainbow trout (Oncorhynchus mykiss). Aquacult. Nutrit., v.8, p.271-277, 2002.

FURUYA, W.M.; GONÇALVES, G.S.; FURUYA, V.R.B. et al. Fitase na alimentação da tilápia-do-nilo (Oreochromis niloticus). Desempenho e digestibilidade. Rev. Bras. Zootec., v.30, p.924-929, 2001.

FURUYA, W.M.; SANTOS, V.G.; BOTARO, D. et al. Níveis de proteína e fitase em rações de terminação para a tilápia-do-nilo (Oreocrhomis niloticus). Arq. Cien. Vet. Zool. Unipar, v.8, p.11-17, 2005.

FURUYA, W.M.; FUJJI, K.M.; SANTOS, L.D. et al. Exigência de fósforo disponível para tilápia-do-nilo (35 a 100g). Rev. Bras. Zootec., v.37, p.961-966, 2008.

GONÇALVES, G.S.; PEZZATO, L.E.; BARROS, M.M. et al. Digestibilidade aparente e suplementação de fitase em alimentos vegetais para tilápia-do-nilo. Acta Sci. Anim. Sci., v.26, p.313-321, 2004.

GONÇALVES, G.S.; PEZZATO, L.E.; PADILHA, P. et al. Disponibilidade aparente do fósforo em alimentos vegetais e suplementação da enzima fitase para tilápia-do-nilo. Rev. Bras. Zootec., v.36, p.1473-1480, 2007.

LI, J.S.; LI, J.L, WU, T.T. Effects of non-starch polissacarides enzyme, phytase and citric acid on activities os endogenous digestive enzymes of tilapia (Oreochromis niloticus x Oreochromis aureus). Aquacult. Nutrit., v.15, p.415-420, 2008.
MOREIRA, J.A.; LOPES, J.B.; VITTI, D.M.S.S. et al. Modelos matemáticos para o estudo do fluxo biológico do fósforo em suínos alimentados com dietas suplementadas com níveis crescentes de fitase. Arq. Bras. Med. Vet. Zootec., v.61, p.420-428, 2009.

NUTRIENT requirements of fish. Washington: National Academic, 1993. 114p.

NWANNA, L.C.; SCHWARZ, F.J. Effect of supplemental phytase on growth, phosphorus digestibility and bone mineralization of common carp (Cyprinus carpio L). Aquacult. Res., v.38, p.1037-1044, 2007.

NWANNA, L.C.; SCHWARZ, F.J. Effect of different levels of phytase on growth and mineral deposition in common carp (Cyprinus carpio, L.). J. Appl. Ichth., v.24, p.574-580, 2008.

OFFICIAL methods of analysis. 16.ed. Washington, DC: AOAC, 1995.

OLIVA-TELES, A.; PEREIRA, J.P.; GOUVEIA, A. et al. Utilization of diets supplemented with microbial phytase by seabass (Dicentrarchus labrax) juvenilis. Aquat. Living Resour., v.11, p.255-259, 1998.

PEZZATO, L.E.; ROSA, M.J.S.; BARROS, M.M. et al. Exigência em fósforo disponível para alevinos de tilápia-do-nilo. Cienc. Rural, v.36, p.1600-1605, 2006.

QUEROL, M.V.M.; QUEROL, E.; PESSANO, E.F.C. et al. Ocorrência da Carpa Húngara, Cyprinus carpio (Linnarus, 1758) e disseminação parasitária, no arroio Felizardo, Bacia do médio Rio Uruguay, Uruguaiana, RS, Brasil. Biod. Pamp., v.3, p.21-23, 2005.

ROCHA, C.B.; POUEY, J.L.O.F.; ENKE, D.B.S. et al. Suplementação de fitase microbiana na dieta de alevinos de jundiá: efeito sobre o desempenho produtivo e as características de carcaça. Cienc. Rural, v.37, p.1772-1778, 2007.

SARDAR, P.; RANDHAWA, H.S.; ABID, M. et al. Effect of dietary microbial phytase supplementation on growth performance, nutrient utilization, body compositions and haemato-biochemical profiles of Cyprinus carpio (L.) fingerlings fed soyprotein-based diet. Aquacult. Nutrit., v.13, p.444-456, 2007. 
SILVA, T.S.C.; FURUYA, W.M.; SANTOS, L.D. et al. Fitase líquida em dieta extrusada para juvenis de tilápia-do-nilo (Oreochromis niloticus). Acta Sci. Anim. Sci., v.29, p.449-455, 2007.

SUÁREZ-MAHECHA, H.; FRANCISCO, A.; BEIRÃO, L.H. et al. Importância de ácidos graxos poli-insaturados presentes em peixes de cultivo e de ambiente natural para a nutrição humana. Bol. Inst. Pesca, v.28, p.101-110, 2002.

SUGIURA, S.H.; GABAUDAN, J.; DONG, F.M. et al. Dietary microbial phytase supplementation and the utilization of phosphorus, trace minerals and protein by rainbow trout [Oncorhynchus mykiss (Walbaum)] fed soybean meal-based diets. Aquacult. Res., v.32, p.583-592, 2001.
SUREK, D.; MAIORKA, A.; DAHLKE, F. et al. Uso de fitase em dietas de diferentes granulometrias para frangos de corte na fase inicial. Cienc. Rural, v.38, p.1725-1729, 2008.

ZHANG, C.; MAI, K.; AI, Q. et al. Dietary phosphorus requirement of juvenile Japanese seabass, Lateolabrax japonicus. Aquaculture, v.255, p.201-209, 2006. 